\title{
LC-MS/MS method for the quantification of carbinoxamine in human plasma
}

\author{
B. Geeta Bhavani, B.M. Gurupadayya*, S. Sharfuddin \\ Department of Pharmaceutical Analysis, JSS College of Pharmacy, JSS University, Mysore - 570015 , \\ Karnataka, India
}

\begin{abstract}
A simple, reverse-phase high performance liquid chromatographic method with mass spectrometric detection (HPLC-MS/MS) was developed for determination of carbinoxamine in human plasma using pargeverine $\mathrm{HCl}$ as an internal standard. The procedure involves a simple protein precipitation technique using BDS HYPERSIL $C_{8}(100 \times 4.6 \mathrm{~mm})$ column. The mobile phase used was acetonitrile: buffer (25mm ammonium formate solution) (80:20). Precipitation was done using acetonitrile and detection was done in MRM mode, using an Electro Spray positive ionization. The ion transition monitored was $(\mathrm{m} / \mathrm{z})$ carbinoxamine $\left(Q_{1}\right.$ Mass: 291.2; $Q_{3}$ Mass: 167.1), Internal standard ( $Q_{1}$ Mass: 338.1; $Q_{3}$ Mass; 167.0). The retention time of carbinoxamine and internal Standard were 1.61 and 1.75 respectively. Method was evaluated in terms of linearity, accuracy, precision, recovery, sensitivity. The simple extraction procedure and short chromatographic runtime make the method suitable for therapeutic drug monitoring studies.
\end{abstract}

\section{Introduction}

Carbinoxamine (CX) (2-[(4-chlorophenyl)-pyridin-2-yl-methoxy]-N, N-dimethyl-ethanamine) (Fig. 1) is an antihistamine of the ethanolamine class. Ethanolamine antihistamines have significant antimuscarinic activity and produce marked sedation in most patients. In addition to the usual allergic symptoms, the drug also treats irritant cough and nausea, vomiting, and vertigo associated with motion sickness. It is also used commonly to treat drug-induced extrapyramidal symptoms as well as to treat mild cases of Parkinson's disease. Rather than preventing the release of histamine, as docromolyn and nedocromil, carbinoxamine competes with free histamine for binding at HA-receptor sites. Carbinoxamine competitively antagonizes the effects of histamine on HA-receptors in the GI tract, uterus, large blood vessels, and bronchial muscle. Ethanolamine derivatives have greater anticholinergic activity than other antihistamines, which probably accounts for the antidyskinetic action of carbinoxamine.<smiles>CN(C)CCOC(c1ccc(Cl)cc1)c1ccccn1</smiles><smiles>C#CCOC(C(=O)OCCN(C)C)(c1ccccc1)c1ccccc1</smiles>

Fig. 1: Chemical structure of carbinoxamine Fig. 2: Chemical structure of pargeverine (IS)

Some analytical methods are developed for the estimation of carbinoxamine includes, LC-Tandem mass spectrometry $(1,2), \mathrm{LC}(3-5)$, and gas chromatography (6) and spectrophotometry (7-9).

Few combination methods also reported for carbinoxamine with of pseudoephedrine hydrochloride in a pharmaceutical dosage form. Analysis was conducted on a CN column (10 microns), with a mobile phase consisting of acetonitrile-methanol-phosphate buffer ( $\mathrm{pH}$ 5.3)-water (10). Carina de et al have developed quantitative determination of carbinoxamine acetaminophen and phenylephrine in tablets by high-performance liquid chromatography (11). Spectrophotometric determination of the antihistamines, carbinoxamine maleate 
and doxylamine succinate, in an N-cetylpyridinium chloride micellar medium (12). Hence, in the present investigation, a new LC-MS/MS method has been reported for the estimation of carbinoxamine in human plasma using pargeverine as an internal standard pargeverine (fig. 2).

\section{Experimental}

Pure samples of carbinoxamine and pargeverine received as gift sample from RL Fine Chemicals Ltd., Bangalore. Solvents such as acetonitrile, methanol and water used were of HPLC grade. All other chemical like ammonium formate used of AR grade.

\section{Chromatographic and mass spectrometry systems and conditions}

The HPLC system was an LC-20 AD series model (Shimadzu), consisted in a binary pump, an in-line degasser, an auto sampler, a column thermostat and an ion trap VL mass spectrometer detector (Bruckner Daltonics $\mathrm{GmbH}$, Germany). The ion transition monitored was: m/z Carbinoxamine ( $\mathrm{Q}_{1}$ Mass: 291.2; $\mathrm{Q}_{3}$ Mass: 167.1), Internal standard pargeverine $\left(\mathrm{Q}_{1}\right.$ Mass: 338.1; $\mathrm{Q}_{3}$ Mass; 167.0). Chromatographic separation was performed at $45^{\circ} \mathrm{C}$ on a BDS HYPERSIL C-8 $100 \times 4.6 \mathrm{~mm} 5 \mu \mathrm{m}$ column, protected by an in-line filter. The HPLC system was coupled to an MS (ABSICEX API 4000) equipped with an electrospray interface (ESI) operated in the positive ionization mode. Chromatographic and mass spectrometric data acquisitions were performed. The optimization of method parameters are shown in Table 1.

Table 1 Optimized HPLC conditions for the estimation of carbinoxamine

\begin{tabular}{|c|c|}
\hline Parameter & Method \\
\hline Stationary Phase (Column) & $\begin{array}{c}\text { BDS Hypersil C8, 100 x 4.6mm } \\
\text { Buffer: 25mm } \\
\text { Mobile phase }\end{array}$ \\
\hline Flow rate & $\begin{array}{c}\text { ACN Buffer(80:20) } \\
\text { ammonium formate solution }\end{array}$ \\
\hline Column temperature & Ambient \\
\hline Volume of injection loop & $5 \mu 1$ \\
\hline Detection limit & Q1=291.1; Q3=167.1 \\
\hline Drug (Carbinoxamine) & Q1=338.1; Q3=167.0 \\
\hline Internal Standard (Pargeverine) & Positive \\
\hline Polarity & 1.61 \\
\hline Internal standard & 1.75 \\
\hline Drug Rt (min) & 3 \\
\hline Internal standard Rt (min) & \\
\hline Run time (min) & \\
\hline
\end{tabular}

\section{Mobile phase}

In order to find the suitable mobile phase, which provides a good ionization and a maximum sensibility of the analytical method, a solvent screening was achieved. In all cases the organic solvent used was acetonitrile, in proportion of 53\% and to water phase were added salts or organic acids in order to modify the conductibility and the $\mathrm{pH}$. It was compared the ratio signal/noise $(\mathrm{S} / \mathrm{N})$ for a standard solution containing carbinoxamine with concentration of $500 \mathrm{ng} / \mathrm{mL}$, both in negative (MS2), positive (MS3) ionization (Fig. 3) and internal standard (Fig. 4). The suitable mobile phase proved to be a mixture of acetonitrile: buffer $(25 \mathrm{~mm}$ ammonium formate solution) (80:20) using ESI positive ionization. The pump delivered it at $1 \mathrm{~mL} / \mathrm{min}$.

\section{Sample preparation}

Plasma samples were prepared as follows in order to be chromatographically analyzed: in an

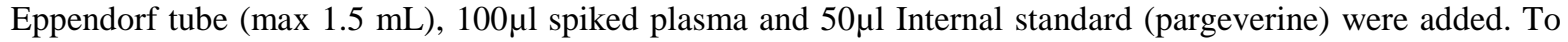
this $500 \mu \mathrm{l}$ of acetonitrile was added. The tube was vortex-mixed for 10min (Vortex Genie 2, Scientific Industries) and centrifuged for $5 \mathrm{~min}$ under $4^{\circ} \mathrm{C}$ at $4500 \mathrm{rpm}$ (Thermo Fischer scientific). The supernatant of $5 \mu \mathrm{l}$ was transferred to an auto sampler vial and was injected into the HPLC system.

\section{Preparation of standard blank and zero standard samples}

The standard blank samples were prepared by transferring $0.5 \mathrm{~mL}$ screened blank plasma into prelabeled vials. The zero standard was prepared by adding $20 \mu \mathrm{L}$ of internal standard solution (pargeverine) (1.0 $\mu \mathrm{g} / \mathrm{mL}$ ) into $0.5 \mathrm{~mL}$ screened blank plasma into a pre-labeled vial and vortex for 15 seconds. 


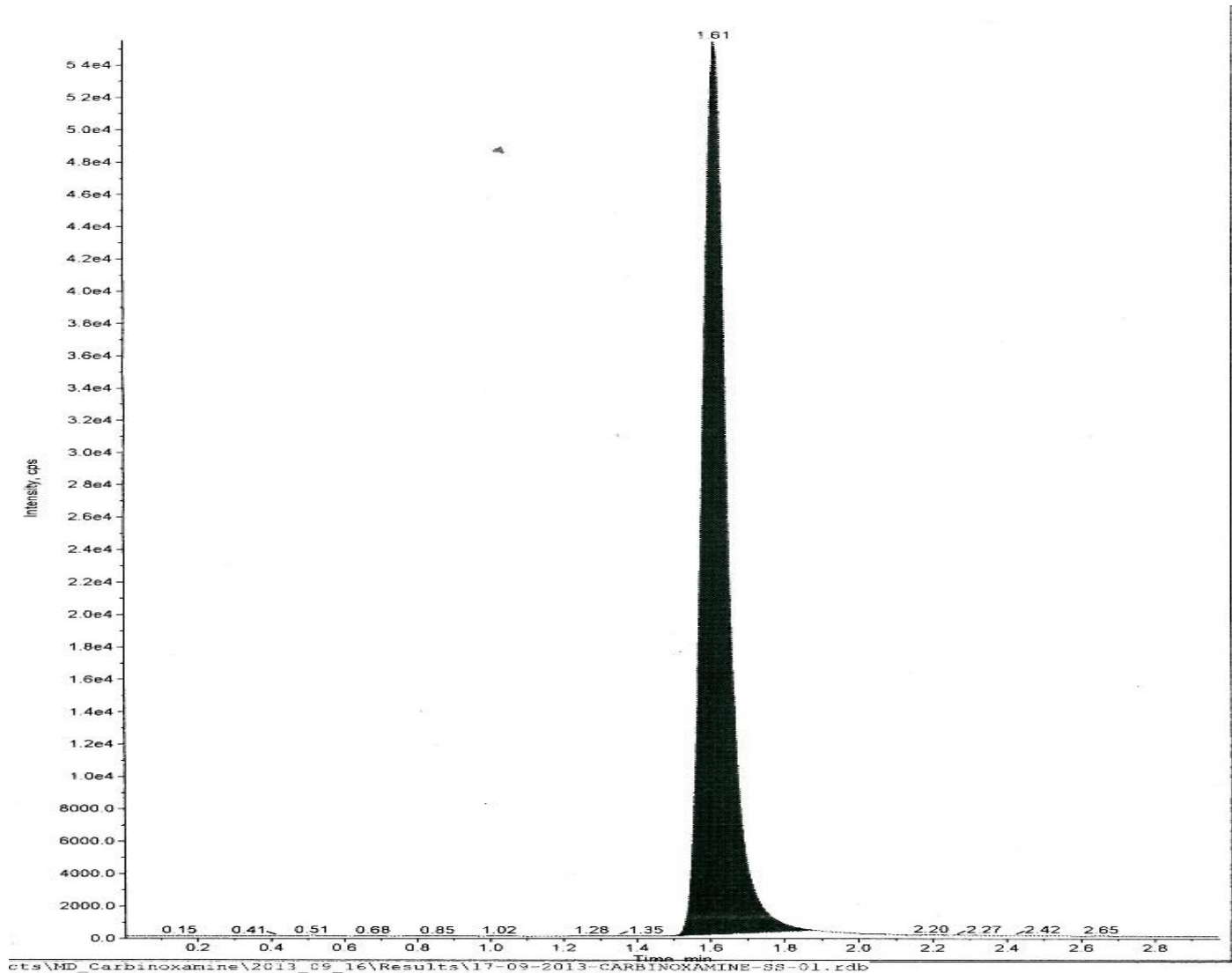

Fig. 3: LCMS Chromatogram of carbinoxamine

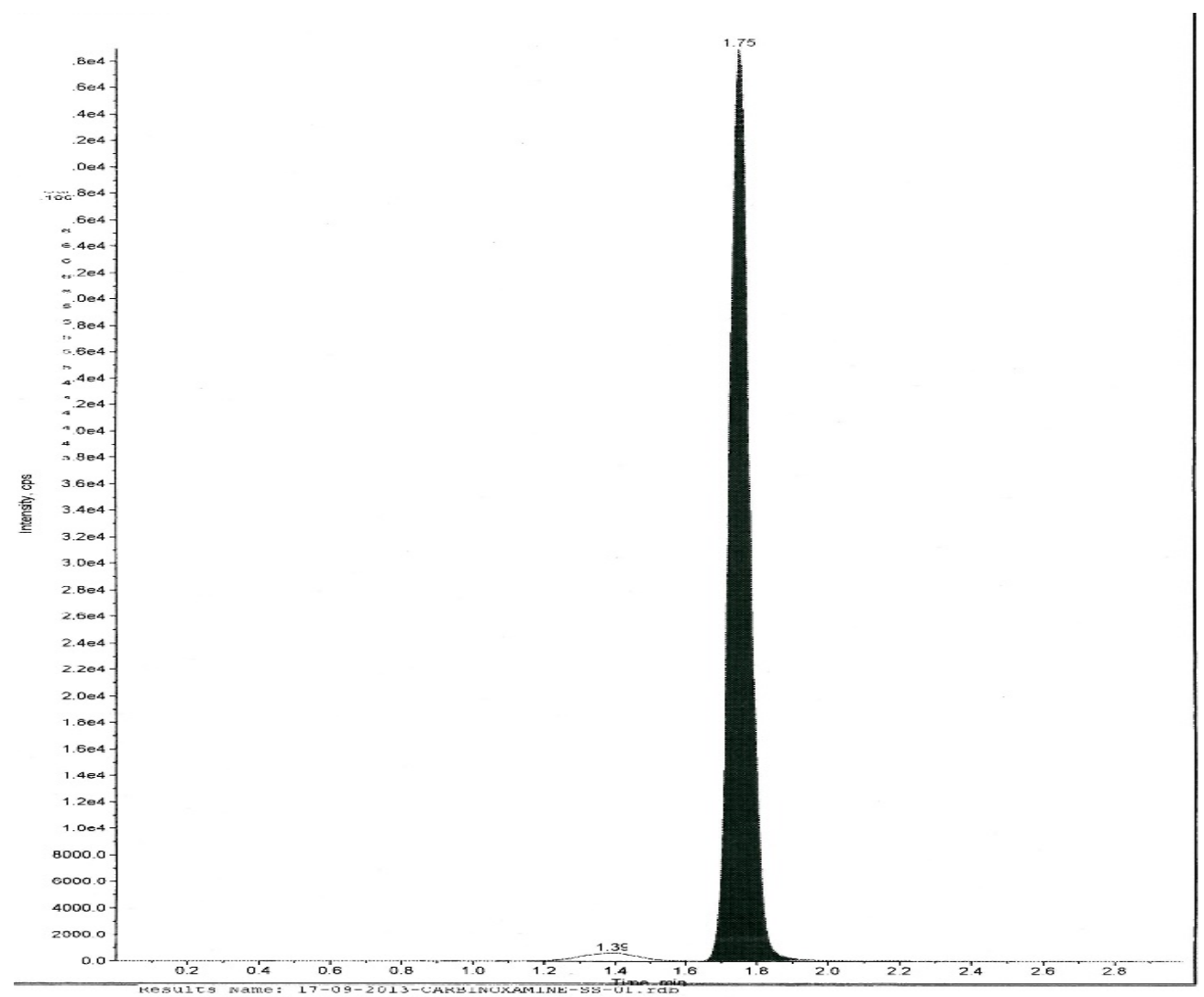

Fig. 4: LCMS Chromatogram of pargeverine internal standard 


\section{Preparation of calibration curve solutions and samples}

The calibration curve standards spiking solutions were prepared by adding $20 \mu \mathrm{L}$ of drug stock solution $(1.0 \mathrm{mg} / \mathrm{mL})$ with diluents (Methanol: Water, 50:50\% v/v) in different vials and add $20 \mu \mathrm{L}$ internal standard pargeverine solution $(1.0 \mu \mathrm{g} / \mathrm{mL})$ and vortex for 15 seconds. Prepare the calibration curve standards by spiking the respective calibration curve standards spiking solutions in screened blank plasma in different vials to obtain final concentration of $5,10,30,50,100,500,1000,3000$ and $5000 \mathrm{ng} / \mathrm{mL}$ of carbinoxamine.

\section{Preparation of quality control solutions and samples}

The quality control spiking solutions were prepared by adding $20 \mu \mathrm{L}$ of drug stock solution $(1.0$ $\mathrm{mg} / \mathrm{mL}$ ) with diluents (Methanol: Water, 50:50\% v/v) in different vials and add $20 \mu \mathrm{L}$ internal standard solution $(1.0 \mu \mathrm{g} / \mathrm{mL})$ and vortex for 15 seconds. Prepare the quality control samples by spiking the respective quality control spiking solutions in screened blank plasma in different vials to obtain lower limit of quantification quality control (LLOQ QC), lower quality control (LQC), middle quality control-2 (MQC2), middle quality control-1 (MQC1), higher quality control (HQC) and upper limit of quantification quality control (ULOQ QC) samples of concentrations of 5, 30, 125, 500, 1250 and $5000 \mathrm{ng} / \mathrm{mL}$ of carbinoxamine. The LLOQ QC and ULLOQ QC solution were prepared only for method validation and screening of blank plasma samples.

\section{Preparation of working solutions for stability testing}

The working spiking solutions were prepared for long-term solution stability and short-term solution stability by adding drug stock solution $(1.0 \mathrm{mg} / \mathrm{mL})$ with diluents (methanol: water, $50: 50 \% \mathrm{v} / \mathrm{v})$ in different vials and vortex for 15 seconds.

\section{Method validation}

The method performance was evaluated for selectivity/selectivity, accuracy, precision, linearity, and limit of detection and limit of quantification etc. [13, 14].

The specificity/selectivity of method was evaluated by analyzing 6 replicates of blank plasma samples and 6 spiked plasma samples at LLOQ (Lower Limit of Quantification $=0.5 \mathrm{ng} / \mathrm{mL}$ ). The chromatographic systems used for analysis should pass the system suitability limits before sample analysis. Set up the chromatographic system, Inject blank preparation (single injection) and standard preparation (six replicates) and record the chromatograms to evaluate the system suitability parameters like resolution (NLT 2.0), tailing factor (NMT 1.5), theoretical plate count (NLT 3000) and \% RSD for peak area of six replicate injections of LMS standard (\%RSD NMT 2.0).

The recovery was evaluated by comparing response of extracted and unextracted samples. Extracted samples include six replicates of extracted LQC, MQC and HQC samples. Unextracted samples included the aqueous solutions equivalent to extracted samples. The average recovery for carbinoxamine in plasma was ranged from 78.32 to $96.84 \%$ for the low, medium and high quality control samples with an average of $88.31 \%$ represented in table 2. The LOQ is defined as the concentration level of carbinoxamine at five times its half-life and providing an $\mathrm{S} / \mathrm{N}$ ratio of 8.7 . The LOQ of carbinoxamine in human plasma was $0.5 \mathrm{ng} / \mathrm{mL}$. The LOD of carbinoxamine was found to be $0.178 \mathrm{ng} / \mathrm{ml}$. Accuracy and precision was evaluated by analysing 3 batches. Each batch consists of six replicates of LQC, MQC and HQC. Precision was evaluated for both interday and intraday batches. The interday and intraday precision and accuracy of the method for each carbinoxamine concentration levels $(20,40$ and $200 \mathrm{ng} / \mathrm{mL})$.

\section{Results and discussion}

The method validation of bioanalysis was performed as stated in US-FDA guideline. Specificity, selectivity, system suitability, \% recovery, linearity, limit of detection, limit of quantitation, accuracy and precision were analyzed.

The specificity/selectivity of the method was investigated by analyzing six blank human plasma extract $(n=6)$ and extract of spiked drug (Table 2). No significant interference in the blank plasma traces was seen from endogenous substances in drug free human plasma at the retention time of the analyte. Under the chromatographic conditions described, carbinoxamine and the internal standard were eluted with nearly the same retention time. System suitability was studied under each validation parameter by injecting six replicates of the standard solution. The system suitability parameters are given in Table 3.

The lower limit of detection (LOD), was shown to be $0.05 \mathrm{ng} / \mathrm{mL}$. The lower limit of quantitation (LLOQ) found to be $0.2 \mathrm{ng} / \mathrm{mL}$ in human plasma. The mean response for analyte peak at the assay sensitivity limit $(0.2 \mathrm{ng} / \mathrm{mL})$ was about 5 fold greater than the mean response for peak in six blank human plasma samples at the retention time of the analyte. The between-batch precision at the LLOQ was $3.475 \%$ and between-batch accuracy was $99.18 \%$ (Table 4 ). 
Table 2: Selectivity data of carbinoxamine

\begin{tabular}{|c|c|c|c|c|c|c|c|c|}
\hline \multirow{2}{*}{$\begin{array}{c}\text { S.N } \\
0\end{array}$} & \multirow[b]{2}{*}{ Matrix } & \multicolumn{6}{|c|}{ Area Response } & \multirow{2}{*}{$\begin{array}{c}\text { Acceptance } \\
\text { (yes/No) }\end{array}$} \\
\hline & & $\begin{array}{c}\text { Analyte } \\
\text { area } \\
\text { (Blank) }\end{array}$ & $\begin{array}{c}\text { Analyte } \\
\text { area } \\
\text { (LLOQ) }\end{array}$ & $\begin{array}{l}\text { ISTD Area } \\
\text { (Blank) }\end{array}$ & $\begin{array}{c}\text { ISTD } \\
\text { Area } \\
\text { (LLOQ) } \\
\end{array}$ & $\begin{array}{c}\text { \% Interfere } \\
\text { nce for } \\
\text { Analyte }\end{array}$ & $\begin{array}{c}\text { \% Interferenc } \\
\text { e for ISTD }\end{array}$ & \\
\hline 1 & Donar-1 & 0 & 4617 & 0 & 273671 & 0.00 & 0.00 & Yes \\
\hline 2 & Donar-2 & 0 & 4606 & 0 & 265291 & 0.00 & 0.00 & Yes \\
\hline 3 & Donar-3 & 0 & 4438 & 366 & 241835 & 0.00 & 0.15 & Yes \\
\hline 4 & Donar-4 & 0 & 4664 & 0 & 240330 & 0.00 & 0.00 & Yes \\
\hline 5 & Donar-5 & 0 & 4318 & 0 & 240429 & 0.00 & 0.00 & Yes \\
\hline 6 & Donar-6 & 0 & 4586 & 0 & 240566 & 0.00 & 0.00 & Yes \\
\hline 7 & N/AP & N/AP & N/AP & N/AP & N/AP & \#Value! & \#Value! & N/AP \\
\hline 8 & N/AP & N/AP & N/AP & N/AP & N/AP & \#Value! & \#Value! & N/AP \\
\hline 9 & N/AP & N/AP & N/AP & N/AP & N/AP & \#Value! & \#Value! & N/AP \\
\hline
\end{tabular}

Table 3: System suitability of carbinoxamine

\begin{tabular}{|c|c|c|c|}
\hline \multirow{2}{*}{$\begin{array}{c}\text { Replicate Injection } \\
\text { No. }\end{array}$} & \multicolumn{2}{|c|}{ Retention Time } & \multirow{2}{*}{ Area Ratio } \\
\cline { 2 - 3 } & Analyte & ISTD & 0.9413 \\
\hline 1 & 1.61 & 1.76 & 0.9518 \\
\hline 2 & 1.61 & 1.76 & 0.9752 \\
\hline 3 & 1.61 & 1.75 & 0.9689 \\
\hline 4 & 1.61 & 1.75 & 0.9888 \\
\hline 5 & 1.61 & 1.75 & 0.9833 \\
\hline 6 & 1.61 & 1.75 & 0.9682 \\
\hline MEAN & 1.61 & 1.75 & 0.0184 \\
\hline SD & 0.0000 & 0.0052 & 1.90 \\
\hline$\%$ CV & 0.00 & 0.30 & \\
\hline
\end{tabular}

Table 4: Recovery studies of carbinoxamine

\begin{tabular}{|c|c|c|c|c|c|c|}
\hline & \multicolumn{6}{|c|}{ Drug } \\
\hline & \multicolumn{2}{|c|}{ LQC } & \multicolumn{2}{|c|}{ MQC } & \multicolumn{2}{|c|}{ HQC } \\
\hline & Aqueous area & Extracted area & Aqueous area & Extracted area & Aqueous area & Extracted area \\
\hline Mean & 10091 & 9772 & 219318 & 196874 & 418369 & 327683 \\
\hline SD & 431 & 167 & 12106 & 2243 & 9839 & 8061 \\
\hline$\% \mathrm{CV}$ & 4.27 & 1.71 & 5.52 & 1.14 & 2.35 & 2.46 \\
\hline \% Recovery & \multicolumn{2}{|c|}{96.84} & \multicolumn{2}{|c|}{89.77} & \multicolumn{2}{|c|}{78.32} \\
\hline
\end{tabular}

Prepared six sets of recovery comparison samples by spiking $50 \mu \mathrm{L}$ of spiking dilution of quality control samples (LQC, MQC, MQC1 and HQC) carbinoxamine of in $950 \mu \mathrm{L}$ eluent of extracted blank. The mean overall recovery of carbinoxamine was $74.61 \%$ with a precision of $4.67 \%$ \& mean recovery of internal standard (pargeverine) was $77.49 \%$. For LLOQQC, the intra-day precision ranged from $4.39 \%$ to $7.39 \%$ and the intra-day accuracy ranged from $99.16 \%$ to $105.55 \%$ for carbinoxamine (Table 5). For LLOQ QC, the inter-day precision was $6.45 \%$ and the inter-day accuracy was $100.29 \%$ for carbinoxamine (Table 6 ). The results showed that for within run and between run experiments the precision and accuracy for the analyte were within the acceptance criteria.

Table 5: Precision study of the method (Intraday)

\begin{tabular}{|c|c|c|c|c|}
\hline Precision & $\begin{array}{c}\text { QC Sample } \\
(\mathbf{n g} / \mathbf{m L}) \\
(\mathbf{n = 6 )}\end{array}$ & $\begin{array}{c}\text { Concentration } \\
\text { found (\%) }\end{array}$ & SD & CV (\%) \\
\hline LQC & 1.442 & 1.338 & 0.076 & 5.68 \\
\hline MQC & 24.03 & 26.943 & 0.702 & 2.61 \\
\hline HQC & 40.05 & 44.539 & 3.300 & 7.41 \\
\hline
\end{tabular}


Table 6: Precision study of the method (Interday)

\begin{tabular}{|c|c|c|c|c|}
\hline Precision & $\begin{array}{c}\text { QC Sample } \\
(\mathbf{n g} / \mathbf{m L}) \\
(\mathbf{n = 6})\end{array}$ & $\begin{array}{c}\text { Concentration } \\
\text { found (\%) }\end{array}$ & SD & CV (\%) \\
\hline LQC & 1.442 & 1.371 & 0.061 & 4.45 \\
\hline MQC & 24.03 & 26.674 & 0.496 & 1.86 \\
\hline HQC & 40.05 & 43.789 & 1.951 & 4.46 \\
\hline
\end{tabular}

The bioanalytical methodology described in this report was specific, sensitive, accurate and precise enough to be successfully applied to pharmacokinetics study. The method employed sample preparation by solid phase micro extraction (SPME) appeared to be adequate recovery including less time consuming, and was followed by gradient HPLC coupled with tandem mass spectrometric detection (LC-MS/MS).

The LC-MS/MS method could be used to determination of carbinoxamine in human plasma, in the concentration range $0.2-80 \mathrm{ng} / \mathrm{mL}$. There were no interferences from endogenous plasma component or other sources. The need for plasma volume less than $250 \mathrm{~mL}$ for each sample made it possible to decrease volume of sample preparation per time. The method was successfully validated and proved appropriate for the analysis of carbinoxamine in human plasma and can be applied for pharmacokinetics studies. The analytical method presented here has proved to be useful for investigation of the characteristics of carbinoxamine in human plasma in pharmacokinetic and pharmacogenetic studies.

\section{Acknowledgments:}

The authors gratefully acknowledge Biocon Industry, Bangalore, India for providing necessary facilities for carrying out this study. The authors express deep sense of gratitude for, to Dr.A.T. Bapuji, Sr.Vice president, Clinical Pharmacology Department, Biocon Industry, Bangalore, for giving the technical support to do the work in their esteemed organization and D. Ramaraju Sr. Scientist for suggesting to take up this work, for constant supervision, valuable advice, and providing platform of work and their technical support and for analytical data required for this work.

\section{References:}

[1] C.A. Mueller, W. Weinmann, S. Dresen, and A. Schreiber, M.Gergov, Development of a multi-target screening analysis for 301 drugs using a QTrap liquid chromatography/tandem mass spectrometry system and automated library searching. Rapid Commun. Mass Spectrum. 19 (2005) 1332-1338.

[2] M. Gergov, I. Ojanpera, and E. Vuori, Simultaneous screening for 238 drugs in blood by liquid chromatography-ion spray tandem mass spectrometry with multiple-reaction monitoring, J. Chromatogr. B Anal. Technol. Biomed. Life Sci. 795 (2003) $41-53$.

[3] J. Esteve-Romero, S. Carda-Broch, M. Gil-Agusti, M.E. Capella-Peiro, and D. Bose. Micellar liquid chromatography for the determination of drug materials in pharmaceutical preparations and biological samples, Trends Anal. Chem. 24 (2005) 75-91.

[4] M. Gil-Agusti, M.E. Capella-Peiro, L. Monferrer-Pons, M.C. Garcia-Alvarez-Coque, and J. Esteve-Romero. Chromatographic analysis of phenethylamine-antihistamine combinations using C8, C18 or cyano columns and micellar sodium dodecyl sulfatepentanol mixtures. Analyst. 126(4) (2001) 457-464.

[5] J. Araujo, J.F. Boyer, M.L. Probecker. Determination of a mixture of phenylpropanolamine hydrochloride and carbinoxamine maleate by high performance liquid chromatography, STP Pharma, 4 (1998), 598-602.

[6] R. Hsu and A.M. Au, Gas chromatography-chemical ionization mass spectrometry for drug screen analyses, Bull. Environ. Contam. Toxicol. 66 (2001) 178-183.

[7] I. Shoukrallah, Determination of phenylephrine hydrochloride and carbinoxamine maleate in capsules and diphenhydramine hydrochloride and naphazoline hydrochloride in nasal jelly by first order derivative UV spectroscopy, Acta Pharm. Jugosl. 41 (1991) $107-115$.

[8] I. Shoukrallah. The Use of First-Order UV Spectroscopy to Determine Binary Mixtures of Pharmaceuticals (A) PHEH and CBOM and (B) DPHH and NPZH, Anal. Lett. 24 (1991) 2043-2058.

[9] A.A. Ramadan, H. Mandil, Spectrophotometric determination of carbinoxamine maleate in pharmaceutical formulations by ternary complex formation with $\mathrm{Cu}(\mathrm{II})$ and eosin, Anal Biochem. 353(1) (2006) 133-137.

[10] A.M. Mansour, Determination of pseudoephedrine hydrochloride and carbinoxamine maleate in combination drug formulation by liquid chromatography, JAOAC Int. 81(5) (1998) 958-962.

[11] A. Carina de, A. Bastose Marcone, L. de Oliveira, Quantitative determination of acetaminophen, phenylephrine and carbinoxamine in tablets by high-performance liquid chromatography, Quim. Nova, (2009) 32(7) 1951-1955.

[12] L Monferrer-Pons, J.S. Esteve-Romero, G. Ramisramos, M.C. Garcia Alavarez-Coque, Spectrophotometric determination of the antihistamines, carbinoxamine maleate and doxylamine succinate, in an N-cetylpyridinium chloride micellar medium, Anal. Lett. 29 1996) 1399-1413.

[13] U. S. Department of Health and Human Services, Food and Drug Administration, Center for Drug Evaluation and Research. Guidance for Industry. Bioavailability and Bioequivalence Studies for Orally Administrated Drug Products - General Considerations, Rockville, USA, 2003, http://www.fda.gov/cder/guidance/index.htm.

[14] U. S. Department of Health and Human Services, Food and Drug Administration, Guidance for Industry - Bio analytical Method Validation, 2001. 